\title{
Motivation in Mathematics of High Functioning Students With Autism Spectrum Disorder (ASD)
}

\author{
Alexandra Georgiou, Spyridon-Georgios Soulis, Danai Rapti \\ Department of Primary Education, University of Ioannina, Ioannina, Greece
}

\begin{abstract}
This study examines the motivation of high functioning students with Autism Spectrum Disorder (ASD) in mathematics according to the achievement goal theory. Specifically, mastery goals, performance goals, performance-avoidance goals, self-efficacy beliefs, fear of failure, and interest in mathematics have been examined. Data were collected from twenty four high functioning students with ASD and a control group of twenty four typically developing students. Findings revealed that high functioning students with ASD presented a significant great fear of failure in mathematics while their self-efficacy beliefs were on an average level. Moreover, the research data revealed that factors such as age, sex, type of school affect and largely determine motivation in mathematics both of high functioning students with ASD and typically developing ones.
\end{abstract}

Keywords: motivation, mathematics, high functioning students with ASD, achievement goal theory

\section{Introduction}

High functioning students with Autism Spectrum Disorders (ASD) are a group of students whose educational needs in mathematics are often a challenge for their teachers (Finnane, 2011). ASD is a developmental disorder diagnosed on the basis of social communication and interaction deficits, as well as restricted, repetitive patterns of behavior, interests or activities (American Psychiatric Association, 2013). According to the latest edition of the diagnostic manual DSM-5 (American Psychiatric Association, 2013) by the American Psychiatric Association (APA), high functioning students with ASD are reported to have difficulty in social contact and communication while they present repetitive stereotypical behavior. This difficulty is considered to be less serious in high functioning students with ASD who have typical or high cognitive skills and realize their grave social communicational difficulties, yet they do not know how to deal with them (Attwood, 2007).

While a number of high functioning students with ASD have exceptional mathematical skills (McMullen, 2000), several studies indicate that the majority of them face significant difficulty in solving problems in mathematics (Chiang \& Lin, 2007). Furthermore, research suggests that children with ASD are given assignments that are challenging or simply unappealing to them (Lynn, Anjileen, \& Robert, 2010). This may lead them to display a mild or severe disruptive behavior in order to avoid these assignments (Ochs, Kremer-Sadlik, Solomon, \& Sirota, 2001). Research indicates that by enhancing and incorporating the choices of high functioning students with ASD in the process of learning, their rate of performance and interest

Alexandra Georgiou, Ph.D. Candidate, Department of Primary Education, University of Ioannina.

Spyridon-Georgios Soulis, Ph.D. in Special Education, Associate Professor, Department of Primary Education, University of Ioannina.

Danai Rapti, Ph.D. Candidate, Department of Primary Education, University of Ioannina. 
improves while their disruptive behavior is reduced (Lynn et al., 2010). Another research points out that students' motivation can be a predictive factor of their performance in mathematics (Bretscher, Dwinell, Hey, \& Higbee, 1989). However, it is noticed that students with ASD are stimulated differently compared to typically developing students (Wagner, 1999). Specifically, although they have the ability to be motivated, the way they are being motivated may not be as appealing as it appears to be in typically developing students (Wagner, 1999).

Nonetheless, one might wonder what exactly motivation in mathematics is. The term motivation is used to describe the degree and the causes of satisfaction of a person (Pantziara \& Filippou, 2006). In mathematics education, the terms of incitement and orientation (Yates, 2000), of interest (Bikner-Ahsbahs, 2003), and convictions (Kloosterman, 2002) have all been used to refer to motivation. In the field of educational psychology, Pintrich (2003) refers to five socio-cognitive theories that examine students' motivation; those theories include the need for success, the fear of failure, the need for autonomy, a student's need to be part of a team, and the need for a sense of self-efficacy.

In the present research, in order to examine the motivation of high functioning students with ASD in mathematics, the "Achievement Goal Theory" has been chosen (Elliot \& Church, 1997; Elliot, 1999). The achievement goal theory focuses on the way students evaluate the actions they are about to commit, as well as on the performance-results that their actions will have (Kaplan \& Machr, 2007). Many variables considered as antecedents of students' motivation constructs have been studied. Some of these variables are: mastery goals, performance goals, and performance avoidance goals. Mastery goals focus on students' ability to understand the material in depth, thus resulting in their ability to improve their learning (Somuncuoglu \& Yildirim, 1999). Performance goals are more related to grades, concerning the students' effort to get better grades or when they tend to avoid the appearance of failure and inability (Dweck \& Leggett, 1998). According to Elliot (1999), performance goals correlate less to the beneficial strategies and the in-depth learning while they are related to grades.

The relationship between achievement goals and student's behavior has been explained through the model of achievement goals (Cury, Elliot, Da Fonseca, \& Moller, 2006; Elliot \& Church, 1997). According to this model, self-efficacy beliefs are motives which urge students to adopt mastery goals and performance goals. At the same time, the fear of failure is a motive that leads students to performance-avoidance goals. Furthermore, students' interest is an important parameter in adopting achievement goals (Pantziara \& Philippou, 2006). Overall, the achievement goals can better interpret the students' cognitive skills, their behavior and their motives in learning in general (Urdan \& Maehr, 1995), and in mathematics in particular (Akin, 2012; Sekreter \& Doghonadze, 2015). It is worth mentioning that although much research has been carried out on educational psychology that examines the achievement goals in mathematics of typically developing students (i.e. Middleton, Kaplan, \& Midgley, 2004; Niepela, Brunner, \& Preckela, 2014; Pantziara \& Philippou, 2006), yet, similar research on high functioning students with ASD is limited. In this respect, the purpose of the present study is to investigate the achievement goals of high functioning students with ASD in mathematics and to examine how those differ from the achievement goals of typically developing students. Besides, other factors examined are the way demographic characteristics such as gender, age, students' view of mathematics (whether they like it or not), the assistance they have at home regarding mathematics, and whether they are in an inclusion class or in parallel support in mathematics affect achievement goals of high functioning students with ASD in mathematics. 


\section{Method}

\section{Research Questions}

With the aforementioned aim in mind, the questions that the present research poses are the following:

(1) How are the achievement goals of high functioning students with ASD evaluated?

(2) Is there a difference between high functioning students with ASD and typically developing children as far as their achievement goals in mathematics are concerned? And

(3) What is the effect of demographic factors on the achievement goals of high functioning students with ASD in mathematics?

\section{Participants}

The empirical material was collected during the year 2017 in the prefectures of Epirus, and Attiki in Greece. Twenty four high functioning students with ASD and 24 typically developing students, who were the control group, took part in the research. All of the high functioning students with ASD have been diagnosed by a Centre of "Diaforodiagnosis", Diagnosis and Support. The participants were of similar socioeconomic background. As far as the high functioning participants with ASD are concerned, eight of them were girls and 16 were boys aged 13 to 17 . In the control group of the typically developing students, half of them were boys and the other half girls, aged 13 to 16. Among the high functioning students with ASD eight attended a special vocational high school, four attended an inclusion class, four had parallel support, and eight of them attended a general high school class.

\section{Research Tool}

Keeping the aforementioned goals in mind, the written questionnaire was chosen to be used as a means of data collection. The questionnaire, which has been used in the present study, is divided into two sections.

The first section contained five questions regarding the demographic and personal characteristics of the participants. More specifically, those five questions concerned the gender, age, the students' views of mathematics: whether they like mathematics or not, the assistance that they have at home regarding mathematics, and whether they attend a special vocational middle or high school class, a general middle or high school class, an inclusion class or have parallel support. Following the decisions of the Minister of National Education in Greece, the integration, study and graduation of students with disability or with special educational needs in general schools entails inclusion classes as well as programs of parallel support. More specifically, the inclusion classes, which students with special educational needs can attend for up to three hours per day, operate within the framework of the general school. The program of parallel support takes place in the general class, which includes students with or without educational needs, where a student with special educational needs is assisted by a special educator during the lesson. Evaluation by the Centre of "Diaforodiagnosis", Diagnosis and Support is a prerequisite for a student with special educational needs in order to attend an inclusion class or receive parallel support.

In the second section, students were given a questionnaire of thirty five statements which are divided into six subscales. Four of the subscales measure mastery goals, performance goals, performance-avoidance goals, and self-efficacy beliefs of the students and are based on the Patterns of Adaptive Learning Strategies-PALS questionnaire (Midgley, Maehr, Hruda, Anderman, Anderman, Freeman, Gheen, Kaplan, Kumar, Middleton, Nelson, Roeser, \& Urdan, 2000). The subscale that measures fear of failure is based on a questionnaire that was developed by Hermans (Elliot \& Church, 1997) and the subscale that measures students' interest in 
mathematics is based on a questionnaire that was developed by Elliot and Church (1997). The questionnaire is a five-point Likert-type scale (1-Totally Disagree to 5-Totally Agree).

\section{Data Analysis}

The SPSS for Windows, version 21.0 (Statistical Package for Social Sciences) was used for the statistical analysis of the research data. The method of descriptive statistics (frequency, mean, standard deviation) was used for the analysis of the descriptive variables. Taking into consideration the size of the sample, nonparametric criteria were used. To be more specific, the Mann-Whitney's U nonparametric test was used in order to examine the difference between the means of two groups in regard to a dependent variable. In cases where there were more than two groups, the Kruskal-Wallis nonparametric criterion was applied. The Spearman Rho correlation coefficient was used to measure the statistical dependence of the subcategories. A significance level of $p=0.05$ was chosen.

The existence of cohesion among the subscales of the questionnaire was examined through the Cronbach index a, which is one of the most widely used credibility indicators (Cronbach, 1951).

It is also called internal consistency coefficient. This index can be interpreted as the degree of correlation between a climax and all the other possible ones, which include the same number of subjects and can be created by a potential total of subjects which measure the specific characteristic. Theoretically, it can range from minus infinity to 1 (only positive values make sense).

Indicative credibility values are the following:

$-<0.6$ the climax is unreliable;

- 0.6 minimum acceptable limit;

- 0.7 sufficient;

- 0.8 better;

- 0.9 extremely high credibility (rather rare).

\section{Results}

Initially, a credibility analysis was performed in order to investigate the internal cohesion of the questionnaire in every subscale. The statements of the subscale "performance-avoidance goals" were found to lack reliable cohesion and, thus, it was ruled out from the research. The values of the alpha index of Cronbach in the rest subscales range from 0.685 to 0.835 , that is to say it is sufficiently very good levels of cohesion.

Table 1 presents the descriptive features of students' achievement goals in mathematics. That is the mean $(\mathrm{M})$, frequency $(\mathrm{N})$ and standard deviation (SD). It can be observed that high functioning students with ASD showed significant lower mastery goals $(p=0.038<0.05)$, significant higher fear of failure $(p=0.005<0.05)$ and significant higher interest in mathematics $(p=0.001<0.05)$ compared to typically developing students (Table 1). In particular, the fear of failure in mathematics of high functioning students' with ASD is quite high $(\mathrm{M}=3.41, \mathrm{SD}=0.33)$, while their self-efficacy beliefs in mathematics were lower $(\mathrm{M}=3.13$, $\mathrm{SD}=0.93)$. Their mastery goals in mathematics range at three levels $(\mathrm{M}=3.01, \mathrm{SD}=1.15)$, meaning that they do not focus on understanding the mathematics in depth. Their performance goal in mathematics is also relatively low $(\mathrm{M}=2.83, \mathrm{SD}=0.77)$, that is they neither focus on grades nor are they comparing their ability in mathematics to that of their classmates. Their interest in mathematics is average as well $(\mathrm{M}=3.12, \mathrm{SD}=0.45)$ (Table 1). 
Typically developing students' fear of failure $(\mathrm{M}=2.83, \mathrm{SD}=0.51)$ and self-efficacy beliefs $(\mathrm{M}=2.92$, $\mathrm{SD}=0.88)$ in mathematics range at average levels. They have high mastery goals $(\mathrm{M}=3.68, \mathrm{SD}=0.78)$, meaning that they focus on understanding mathematics in depth. However, performance goals $(M=2.45)$ and interest $(\mathrm{M}=2.50, \mathrm{SD}=0.24)$ of typically developing students range at average levels (Table 1$)$.

Table 1

Descriptive Statistics of Students' Achievement Goals in Mathematics

\begin{tabular}{lllllll}
\hline & & Mastery Goals & $\begin{array}{l}\text { Performance } \\
\text { Goals }\end{array}$ & $\begin{array}{l}\text { Self-efficacy } \\
\text { beliefs }\end{array}$ & Fear of failure & Interest \\
\hline \multirow{2}{*}{ Students in } & Mean & 3.01 & 2.83 & 3.13 & 3.41 & 3.12 \\
ASD & Range & 3.40 & 1.80 & 2.60 & 0.78 & 1.29 \\
& S.D. & 1.15 & 0.77 & 0.93 & 0.33 & 0.45 \\
Typical & Mean & 3.68 & 2.45 & 2.92 & 2.83 & 2.50 \\
Students & Range & 3.20 & 3.60 & 3.20 & 2.00 & 0.71 \\
Sig. $(p)$ & S. D. & 0.78 & 1.17 & 0.88 & 0.51 & 0.24 \\
\hline
\end{tabular}

Table 2

Comparing Achievement Goals of High Functioning Students With ASD Regarding Their Demographic or Personal Characteristics

\begin{tabular}{|c|c|c|c|c|c|}
\hline & Mastery goals & $\begin{array}{l}\text { Performance } \\
\text { Goals }\end{array}$ & $\begin{array}{l}\text { Self-efficacy } \\
\text { beliefs }\end{array}$ & Fear of failure & Interest \\
\hline Sex & 0.792 & 0.694 & 0.568 & 0.140 & $0.003^{*}$ \\
\hline Age & 0.731 & 0.562 & 0.513 & $0.009^{*}$ & $0.000^{*}$ \\
\hline Assistance in mathematics & 0.495 & 0.495 & $0.040^{*}$ & 0.150 & $0.039^{*}$ \\
\hline Type of school & 0.580 & $0.018^{*}$ & $0.027^{*}$ & $0.002^{*}$ & 0.643 \\
\hline
\end{tabular}

Note. $* p<0.05$.

In addition, the effect of the students' demographic and personal characteristic on their achievement goals in mathematics was examined (Table 2). The Mann-Whitney's U nonparametric test was used in order to examine the difference between the means of two groups in each test variable (achievement goal) in regard to the grouping variable (demographic and educational characteristic). In cases where the grouping variable has more than two independent samples the Kruskal-Wallis nonparametric criterion was applied.

Specifically, regarding high functioning students with ASD, their gender has a statistically important effect on their interest in mathematics $(p=0.003)$. It has been observed that high functioning boys with ASD $(\mathrm{M}=3.35, \mathrm{SD}=1.05)$ are more interested in mathematics than high functioning girls with ASD $(\mathrm{M}=2.64, \mathrm{SD}$ $=0.89$ ). Also, it was evident that their age has a statistically important effect on their fear of failure in mathematics $(p=0.009)$ and their interest in mathematics $(p=0.000)$. The older high functioning students with ASD, aged $17(\mathrm{M}=3.77, \mathrm{SD}=0.76)$, appear to have more fear of failure in mathematics than the younger ones, aged 14 years old $(M=3.00, S D=0.32)$. High functioning students with ASD aged 14 years old appear to be more interested in mathematics $(\mathrm{M}=3.85, \mathrm{SD}=0.43)$ compared to high functioning students with $\mathrm{ASD}$, aged 15 years old $(\mathrm{M}=2.64, \mathrm{SD}=0.67)($ Table 2$)$.

High functioning students with ASD who receive assistance in mathematics by a tutor at home present statistically important higher self-efficacy beliefs $(\mathrm{M}=4.00, \mathrm{SD}=0.42)$ compared to high functioning students with ASD who receive assistance in mathematics by their parents at home $(\mathrm{M}=2.40, \mathrm{SD}=0.93)(p=0.040)$. 
Moreover, high functioning students with ASD who receive assistance in mathematics by a tutor at home present statistically important higher interest $(\mathrm{M}=3.85, \mathrm{SD}=0.53)$ compared to high functioning students with ASD who receive assistance in mathematics by their parents at home $(\mathrm{M}=3.04, \mathrm{SD}=0.61)(p=0.039)$ (Table 2).

What is more, the educational support of high functioning students with ASD received in mathematics has a statistically important effect on their performance goals $(p=0.018)$, self-efficacy beliefs $(p=0.027)$ and fear of failure in mathematics.

The highest performance goals were found in high functioning students with ASD who have parallel support in mathematics $(\mathrm{M}=3.40, \mathrm{SD}=0.97)$, followed by those who attend a special vocational high school $(\mathrm{M}=3.30, \mathrm{SD}=0.75)$. High functioning students with ASD who attend a general class in mathematics have quite low performance goals $(\mathrm{M}=2.70, \mathrm{SD}=1.02)$, while those who attend an inclusion class in mathematics have the lowest among all $(\mathrm{M}=1.60, \mathrm{SD}=0.22)$. High self-efficacy beliefs characterised the high functioning students with ASD who attend a special vocational high school $(\mathrm{M}=4.10, \mathrm{SD}=0.84)$, followed by those who attend an inclusion class in mathematics $(\mathrm{M}=3.20, \mathrm{SD}=0.91)$ while high functioning students who have parallel support in mathematics $(\mathrm{M}=2.40, \mathrm{SD}=0.32)$ or attend the general class in mathematics $(\mathrm{M}=2.50, \mathrm{SD}$ $=0.42$ ) appear to have the lowest self-efficacy beliefs. It is particularly interesting that high functioning students with ASD who attend a general class appear to have the greatest fear of failure $(\mathrm{M}=3.77, \mathrm{SD}=0.13)$, followed by those who have parallel support in mathematics $(\mathrm{M}=3.44, \mathrm{SD}=0.34)$, then followed by high functioning students with ASD who attend a special vocational high school $(\mathrm{M}=3.22, \mathrm{SD}=0.40)$ and, finally, by those who attend an inclusion class in mathematics $(\mathrm{M}=3.00, \mathrm{SD}=0.31)$ (Table 2).

Regarding typically developing students, their gender has a statistically important effect on their interest in mathematics ( $p=0.049)$ which is in accordance with the high functioning students with ASD. Specifically, as in high functioning students with ASD, it has been observed that typically developing boys $(\mathrm{M}=2.64, \mathrm{SD}=$ $0.85)$ are more interested in mathematics than typically developing girls $(\mathrm{M}=2.35, \mathrm{SD}=0.43)$ (Table 3$)$.

It is of particular interest that the assistance typically developing students receive in mathematics has a statistically important effect on their performance goals in mathematics $(p=0.045)$. Specifically, typically developing students who are given assistance in mathematics by a tutor at home have higher performance goals $(\mathrm{M}=3.46, \mathrm{SD}=0.78)$ compared to those who do not receive assistance in mathematics at home $(\mathrm{M}=1.60, \mathrm{SD}$ $=0.43)($ Table 3$)$.

Table 3

Investigation of the Achievement Motivation Regarding Demographic Characteristics of Typically Developing Students

\begin{tabular}{llllll}
\hline & Mastery goals & Performance goals & $\begin{array}{l}\text { Self-efficacy } \\
\text { beliefs }\end{array}$ & Fear of failure & Interest \\
\hline Sex & 0.260 & 0.172 & 0.053 & 1.000 & $0.049^{*}$ \\
Age & 0.175 & 0.052 & 0.052 & 0.507 & 0.059 \\
Assistance in mathematics & 0.497 & $0.045^{*}$ & 0.416 & 0.211 & 0.094 \\
\hline
\end{tabular}

Note. $* p<0.05$.

Furthermore, there was a correlation of participants' achievement goals in mathematics according to the Spearman Rho correlation coefficient. More specifically, regarding the high functioning students with ASD, there was a strong positive correlation between their mastery goals and their self-efficacy beliefs $\left(r_{\mathrm{s}}=0.73, p=\right.$ 
0.020) while there was a strong negative correlation between their interest and their fear of failure in mathematics $\left(\mathrm{r}_{\mathrm{s}}=-0.65, p=0.040\right)$ (Table 4$)$.

Table 4

Correlation Coefficients (Spearman Rho) Among Achievement Motives in Mathematics for High Functioning Students With ASD

\begin{tabular}{llllll}
\hline & 1 & 2 & 3 & 4 & 5 \\
\hline Mastery goals (1) & 1 & 0.086 & $0.020^{*}$ & 1.00 & 0.420 \\
Performance goals (2) & & 1 & 0.204 & 0.222 & 0.204 \\
Self-efficacy beliefs (4) & & 1 & 0.252 & 0.791 \\
Fear of failure (5) & & & 1 & $0.040^{*}$ \\
Interest (6) & & & & 1 \\
\hline
\end{tabular}

Note. $* p<0.05$.

Table 5

Correlation Coefficients (Spearman Rho) Among Achievement Motives in Mathematics for Typically Developing Students

\begin{tabular}{llllll}
\hline & 1 & 2 & 3 & 4 & 5 \\
\hline Mastery goals (1) & 1 & 0.862 & 0.268 & 0.570 & 0.647 \\
Performance goals (2) & & 1 & 0.594 & 0.166 & $0.003^{*}$ \\
Self-Efficacy beliefs (4) & & & 1 & 0.627 & 0.428 \\
Fear of failure (5) & & & 1 & $0.041^{*}$ \\
Interest (6) & & & & 1 \\
\hline
\end{tabular}

Note. ${ }^{*} p<0.05$.

Respectively, regarding typically developing students there was a strong positive correlation between their interest and their performance goals in mathematics $\left(\mathrm{r}_{\mathrm{s}}=0.67, \mathrm{p}=0.003\right)$ and also between their interest and their fear of failure in mathematics $\left(r_{s}=0.75, p=0.041\right)$ (Table 5).

At this point, it is notable that the fear of failure in mathematics of high functioning students with ASD increases as their interest in mathematics decreases. On the contrary, it has been observed that the typically developing students' fear of failure in mathematics increases as their interest in mathematics increases.

\section{Discussion}

The findings of the present study highlight the importance of motivation in mathematics for high functioning students with ASD. However, the results suggest that their motives in mathematics are different compared to those of typically developing students. Our results are consistent with previous studies which show that students with ASD, although they can be motivated, they are being motivated differently compared to typically developing ones (Wagner, 1999).

Moreover, high functioning students with ASD presented greater fear of failure in mathematics in comparison to typically developing ones. This can be interpreted by the fact that high functioning students with ASD focus and insist on details and often tend to be perfectionists (Attwood, 2007). Therefore, even a minor mistake in mathematics can cause a sense of failure to them. According to the model of achievement goals, the great fear of failure and the low self-efficacy beliefs of high functioning students with ASD in mathematics do not motivate them to set mastery and performance goals, resulting in their low interest in mathematics. 
Despite their great fear of failure in mathematics, high functioning students' with ASD interest and mastery goals in mathematics are on an average level. On the contrary, typically developing students' mastery goals in mathematics are high, while their interest in mathematics is low. Previous researches have shown that students who set mastery goals exhibit positive behavior, such as self-confidence and internal motivation for learning, as well as a positive attitude towards learning (Elliot, Shell, Henry, \& Maier, 2005; Kaplan \& Maehr, 2007). Furthermore, it has been found that mastery goals are related to students' insistence on mathematical activities, as well as their use of cognitive and post-cognitive learning strategies in mathematics (Wolters, 2004). Taking into consideration those researches and our results, math teachers should focus on reducing the fear of failure of high functioning students with ASD and increase their mastery goals so that they are able to improve their learning and increase their interest in the subject.

Another important finding of this study is the effect that the students' gender, age, the assistance that they receive in mathematics at home, and the educational support they receive at school have on their achievement goals in mathematics. Specifically, regarding their age, it was found that older high functioning students with ASD, compared to younger ones, face greater fear of failure in mathematics, while having lower mastery and performance goals in mathematics. These results are in accordance with the results of researches, where it is recorded that the performance of high functioning students with ASD tends to be reduced as the student moves on classes at school (Goldstein, Minshew, \& Siegal, 1994).

Moreover, the gender of the students significantly affects both typically developing students and high functioning students with ASD. More particularly, in both groups of students boys show greater interest in mathematics than girls. Recent research has shown that boys with ASD are different from girls with ASD and that the learning procedure for boys is different from the learning procedure for girls (Lai, Lombardo,Ruigrok, Chakrabarti, Wheelwright, Auyeung, Allison, MrcAims, \& Baron-Cohen, 2012). Moreover, previous researches in secondary education report that girls tend to have lower self-efficacy beliefs and participation in activities related to mathematics (Anderman \& Young, 1994; Leder \& Forgasz, 2002; Pajares, 1996; Pintrich \& De Groot, 1990), while other researches mention that boys and girls present differences in learning mathematics, which are more obvious in adolescence (Bleeker \& Jacobs, 2004; Urdan \& Midgley, 2003).

Furthermore, it is quite interesting that high functioning students with ASD, who attend a class of general high school without parallel support or attend an inclusion class in mathematics, have low performance goals and self-efficacy beliefs, while they show great fear of failure in mathematics. What is more, the high functioning students with ASD who receive assistance in mathematics at home have high self-efficacy beliefs and interest. Those findings highlight the role and importance of the math teacher for high functioning students' with ASD motivation in mathematics. Therefore, high functioning students with ASD need specialized teaching in mathematics by teachers with specialized knowledge.

Regarding the correlations of factors of motivation in mathematics there is no agreement between high functioning students with ASD and typically developing students. More specifically, there is a positive correlation between the mastery goals of high functioning students with ASD and their self-efficacy beliefs in mathematics. This finding is in accordance with previous researches (Middleton \& Midgley, 2002; Wolters \& Rosenthal, 2000; Elliot, 1999) which found that there is a high positive correlation between the mastery goals and self-efficacy beliefs of high functioning students with ASD in mathematics. To be more specific, those researches argue that mastery goals in mathematics focus on students mastering an activity in such a way that 
leads them towards a more positive prospect in mathematics. As a result, motivating high functioning students with ASD to set mastery goals in mathematics is an educator's important teaching goal since those mastery goals are positively correlated to the students' self-efficacy beliefs.

Furthermore, what is of particular interest is the negative correlation between the interest and fear of failure in mathematics of high functioning students with ASD, and the positive correlation between the typically developing students' interest and fear of failure in mathematics. This finding is not in accordance with previous researches (Pantziara \& Philippou, 2015; Wolters \& Rosenthal, 2000) which demonstrated that typically developing students' interest in mathematics has a statistically important negative correlation to their fear of failure in mathematics.

Moreover, the research indicates that typically developing students' interest in mathematics has a positive correlation to their performance goals in mathematics. This finding is not in accordance with previous researches that found no correlation between performance goals and interest in learning (Elliot et al., 2005; Cury et al., 2006). However, this finding may be explained because typically developing students' interest in mathematics has been found to be related to their performance (Ryan \& Deci, 2000; Harackiewicz, Barron, Carter, Lehto, \& Elliot, 1997). As a result, there is an increase in typically developing students' fear of failure in mathematics. On the other hand, high functioning students with ASD do not often have the same expectations regarding their performance in mathematics. At this point, caution should be taken when interpreting the results of the correlation analyses. The exploration of associations between achievement goals was carried out as exploratory analysis, and no a priori power analysis was conducted to establish that the study had adequate power for this secondary aim. Future studies using larger sample sizes are warranted to further investigate relations between achievement goals of high functioning students with ASD.

What is clear is that the current study predicts impairments in achievement goals of high functioning students with ASD in mathematics comparing to the achievement goals of typically developing students. Although the study of motivation in mathematics of high functioning students with ASD is in its infancy, a sustained study would be fruitful. Particularly, the study of motivation in mathematics of high functioning students with ASD can shape and improve the current educational practice in mathematics by taking into account their special educational needs. It is very important that math teachers encourage their students to develop positive feelings and motives during their teaching by applying learning strategies which cater for their differentiated needs.

\section{Limitations}

At this point, it would be useful to mention certain limitations. First of all, the results of the current study cannot be generalised due to the small size of the sample. Another important limitation is the fact that the unique cognitive profile of high functioning students with ASD makes their matching to another group of students especially problematic (Mayes \& Calhoun, 2006). Finally, another limitation of this research is the age of the students. More specifically, there were no young students taking part in the research whose motivation in mathematics might have been significantly different compared to that of students of older age.

\section{References}

Akin, A. (2012). Achievement goal orientations and math attitudes. Studia Psychologica, 54(3), 237-249.

American Psychiatric Association. (2013). Diagnostic and statistical manual of mental disorders (5th ed.). Washington, DC: American Psychiatric Association. 
Anderman, E. M., \& Young, A. J. (1994). Motivation and strategy use in science: individual differences and classroom effects. Journal of Research in Science Teaching, 31(8), 811-831.

Attwood, T. (2007). The complete guide to Asperger's syndrome. London: Jessica Kingsley Publishers.

Bikner-Ahsbahs, A. (2003). A social extension of a psychological interest theory. In N. A. Pateman, B. J. Dougherty, \& J. Zilliox (Eds.), Proceedings of the 27th Conference of the International Group for the Psychology of Mathematics Education (Vol. 2, pp. 97-104). Honolulu: College of Education, University of Hawaii.

Bleeker, M. M., \& Jacobs, J. E. (2004). Achievement in math and science: Do mothers' beliefs matter 12 years later? Journal of Educational Psychology, 96(1), 97-109.

Bretscher, A. S., Dwinell, P. L., Hey, N. S., \& Higbee, J. L. (1989). Success or failure: Variables affecting mathematics performance. Paper presented at the National Association of Developmental Education, Cincinnati, OH (ERIC Document Reproduction Service No: ED 304340).

Chiang, H., \& Lin, Y. (2007). Mathematical ability of students with Asperger syndrome and high-functioning autism: A review of literature. Autism, 11(6), 547-556.

Cronbach, L. J. (1951). Coefficient alpha and the internal structure of tests. Psychometrika, 16, 297-334 (28,307 citations in Google Scholar as of 4/1/2016).

Cury, F., Elliot, A. J., Da Fonseca, D., \& Moller, A. (2006). The social-cognitive model of achievement motivation and the $2 \times 2$ achievement goal framework. Journal of Personality and Social Psychology, 90(4), 666-679.

Dweck, C. S., \& Leggett, E. L. (1998). A social cognitive approach to motivation and personality. Psychological Review, 95(2), 256-273.

Elliot, A. (1999). Approach and avoidance motivation and achievement goals. Journal of Educational Psychology, 80(3), 260-267.

Elliot, A., \& Church, M. (1997). A hierarchical model of approach and avoidance achievement motivation. Journal of Personality and Social Psychology, 72(1), 218-232.

Elliot, A. J., Shell, M. M., Henry, K. B., \& Maier, M. A. (2005). Achievement goals, performance contingencies, and performance attainment: An experimental test. Journal of Educational Psychology, 97(4), 630-640.

Finnane, M. (2011). Promoting an understanding of mathematical structure in students with high functioning autism. In J. Clark, B. Kissane, J. Mousley, T. Spencer, \& S. Ihorto (Eds.), Mathematics: Traditions and New Practices. Adelaide, SA: AAMI and MF RGA.

Goldstein, G., Minshew, N. J., \& Siegal, D. J. (1994). Age differences in academic achievement in high-functioning autistic individuals. Journal of Clinical and Experimental Neuropsychology, 16(5), 671-680.

Harackiewicz, J. M., Barron, K. E., Carter, S. M., Lehto, A. T., \& Elliot, A. J. (1997). Predictors and consequences of achievement goals in the college classroom: Maintaining interest and making the grade. Journal of Personality and Social Psychology, 73(6), 1284-1295.

Kaplan, A., \& Maehr, M. (2007). The contributions and prospects of goal orientation theory. Educational Psychology Review, $19(2), 141-184$.

Kloosterman, P. (2002). Beliefs about mathematics and mathematics learning in the secondary school: Measurement and implications for motivation. In G. C. Leder, E. Pehkonen, \& G. Torner (Eds.), Beliefs: A hidden variable in mathematics education (pp. 247-269). Kluwer: Dordrecht.

Lai, M. C., Lombardo, M. V., Ruigrok, A. N., Chakrabarti, B., Wheelwright, S. J., Auyeung, B., Allison, C., MrcAims, C., \& Baron-Cohen, S. (2012). Cognition in Males and Females with Autism: Similarities and Differences. PLoS ONE, 7(10), e47198.

Leder, G. C., \& Forgasz, H. J. (2002). Two new instruments to probe attitudes about gender and mathematics. Technical report, ERIC Resources in Education ED463312.

Lynn, K. K., Anjileen, K. S., \& Robert, L. K. (2010). Improving motivation for academics in children with autism. Autism and Developmental Disorders, 40(9), 1057-1066.

Mayes, S. D., \& Calhoun, S. L. (2006). Frequency of reading, math, and writing disabilities in children with clinical disorders. Learning and Individual Differences, 16(2), 145-157.

McMullen, P. (2000). The Gifted Side of Autism. Focus on Autism and Other Developmental Disabilities, 15(4), $239-242$.

Middleton, M. J., Kaplan, A., \& Midgley, C. (2004). The change in middle school students achievement goals in math over time. Social Psychology of Education, 7(3), 289-311.

Middleton, M. J., \& Midgley, C. (2002). Beyond motivation: Middle school students' perceptions of press for understanding in math. Contemporary Educational Psychology, 27(3), 373-391. 
Midgley, C., Maehr, M. L., Hruda, L. Z., Anderman, E., Anderman, L., Freeman, K. E., Gheen, M., Kaplan, A., Kumar, R., Middleton, M. J., Nelson, J., Roeser, R., \& Urdan, T. (2000). Manual for the patterns of adaptive learning scales (PALS). Ann Arbor, MI: University of Michigan.

Niepel, C., Brunner, M., \& Preckel, F. (2014). The longitudinal interplay of students' academic self concepts and achievements within and across domains: replicating and extending the reciprocal internal/external frame of reference model. Journal of Educational Psychology,106(4), 1170-1191.

Ochs, E., Kremer-Sadlik, T., Solomon, O., \& Sirota, K. (2001). Inclusion as social practice: Views of children with autism. Social Development, 10(3), 399-419.

Pajares, F. (1996). Self-efficacy beliefs in achievement settings. Review of Educational Research, 66(4), 543-578.

Pantziara, M., \& Philippou, G. (2006). Measuring and relating primary school students' motives, goals and perfomance in mathematics. In J. Novotná, H. Moraová, M. Krátká, \& N. Stehlíková (Eds.), Proceedings from: 30th Conference of the International Group for the Psychology of Mathematics Education (Vol. 4, pp. 321-328). Prague: PME. 4-321.

Pantziara, M., \& Philippou, G. (2015). Students' Motivation in the Mathematics Classroom. Revealing Causes and Consequences. International Journal of Science and Mathematics Education, 13(2), 385-411.

Pintrich, P. (2003). A motivational science perspective on the role of student motivation inlearning and teaching contexts. Journal of Educational Psychology, 95(4), 667-686.

Pintrich, P. R., \& De Groot, E. V. (1990). Motivational and self-regulated learning componentsof classroom academic performance. Journal of Educational Psychology, 82(1), 33-40.

Ryan, R. M., \& Deci, E. L. (2000). Self-determination theory and the facilitation of intrinsicmotivation, social development, and well-being. American Psychologist, 55(1), 68-78.

Sekreter, G., \& Doghonadze, N. (2015). Applications of Goal Theory to Teaching Mathematics. Journal of Education in Black Sea Region, 1(1), 65-73.

Somuncuoglu, Y., \& Yildirim, A. (1999). Relationship between achievement goal orientationand use of learning strategies. The Journal of Educational Research, 92(5), 267-277.

Urdan, T., \& Maehr, M. (1995). Beyond a Two-Goal Theory of Motivation and Achievement: A Case for Social Goals. Review of Educational Research, 65(3), 213-243.

Urdan, T., \& Midgley, C. (2003). Changes in the perceived classroom goal structure and patternof adaptive learning during early adolescence. Contemporary Educational Psychology, 28(4), 524-551.

Wagner, S. (1999). Inclusive Programming for Elementary students with autism. Arlington TX: Future Horizons Inc.

Wolters, C. (2004). Advancing achievement goal theory: using goal structures and goal orientationsto predict students' motivation, cognition, and achievement. Journal of Educational Psychology, 96, 236-250.

Wolters, C. A., \& Rosenthal, H. (2000). The relation between students' motivational beliefs andtheir use of motivational regulation strategies. International Journal of Educational Research, 33(7-8), 801-820.

Yates, S. M. (2000). Student optimism, pessimism, motivation and achievement in mathematics:A longitudinal study. In T. Nakahara, \& M. Koyama (Eds.), Proceedings from: The $24^{\text {th }}$ Conference of the International Group for the Psychology of Mathematics Education (Vol. 4, pp. 297-304). Japan: Hiroshima University. 